\title{
Actualization of Learning by Developing (LbD): An Analysis
}

\author{
doi:10.3991/ijet.v4s3.1103 \\ R. Pirinen \\ Laurea University of Applied Sciences, Espoo, Finland
}

\begin{abstract}
Learning by Developing (LbD) is a pedagogical and collective approach to learning in which learning is linked to an applied research and development culture. This refers to learning expertise that arises from social interaction, the sharing of knowledge and competence arising from, research and problem solving related to authentic objectives. In this paper, the analysis of LbD's design, development and evaluation work is addressed in relation to the actualization of the three statutory tasks of Finnish university of applied sciences, which are education, research and development, and regional development. Also included is an analysis of action research based on the evaluations performed by the Finnish Higher Education Evaluation Council. The time period of analysis is 20032009.
\end{abstract}

Keywords-Action research, competence creation, innovation system, integrative action model, Learning by Developing, qualitative analysis

\section{INTRODUCTION}

The mission of a Finnish university of applied sciences is to be a workplace-oriented, regional, multidisciplinary and international promoter of its students' professional growth. This means that students develop and co-create the kind of expertise that guarantees their advancement in the world of work in both local and global markets. The statutory task of a university of applied sciences is to provide higher education, which is focused on competences that require professional expertise and are based on the requirements of the labour market, its development, scientific research and also on artistic principles. Thus, it supports the professional development of individuals and carries out research and development work in the service of the development of education, the labour market and regional development, while taking into account the social structures of the region in question.

Universities of applied sciences provide and develop adult education in order to maintain and increase workplace competence. In completing their tasks, universities of applied sciences collaborate with representatives of industries and other employers, particularly in their own region, and also with Finnish and foreign higher education institutions and other educational establishments. If higher education is based on the demands of the employment market, then it is taken as given that universities of applied sciences and the world of work must work together closely. Research conducted by students, which is often related to the future development demands of the employment market, can be used in the workplace to generate new competences, promote regional development, and help to fulfil the three statutory tasks given to the Finnish universities of applied sciences: education; research and development; and regional development [1].

The research scope in this analysis includes the actualization materials related to the statutory learning and education task and the documentation of the two cycles of the action research which were evaluated by the Finnish Higher Education Evaluation Council (FINHEEC) between 2003 and 2006 and 2006 and 2009 [51, 52, 33]; and the evaluation documentation related to education and Learning by Developing 2003-2009 [60, 15, 47].

The organization analyzed is Laurea University of Applied Sciences, Finland. Laurea was appointed as a Centre of Excellence in Regional Development for 20032004 and 2006-2007, and as a Centre of Excellence in Education for 2005-2006 and 2008-2009.

The main activities and results of the actualization of regional development task are presented in [36, 37, 39, ] and a perspective on the research and development task is referenced in [34, 24].

The overarching research question to be investigated in the author's ongoing dissertation study is: How were the three tasks of the universities of applied science actualized at Laurea University of Applied Sciences from 2003 to 2009 ?

The most important questions for this analysis are: 1) What is the theoretical background of Learning by Developing? 2) What models and constructions were developed and tested in the actualization? 3) What results, impacts, educational differences, influences and challenges were observed in the actualization? 4) What new data concepts have been observed and what products have been developed and demonstrated at Laurea University of Applied Sciences? The last question concerns the perspective of education between 2003 and 2008 at Laurea University of Applied Sciences.

\section{BACKGROUND}

\section{A. Pedagogical Literature Formulation}

The theoretical background of education in Learning by Developing and its actualization is related to educational, psychological and sociological theories. The theories behind the three perspectives or metaphors of learning [32] and the theories that are related to the Networked Expertise are explained in $[19,18]$.

The main theoretical background of Laurea's learning culture includes a combination of concepts, models, and innovative development theories. It is a pedagogical approach which has constructively and incrementally 
developed into the present framework of a proactive learning culture called Learning by Developing (LbD), described in Fränti and Pirinen [15, 42, 47].

Yrjö Engeström studied innovative learning cycles in teams by using the cultural-historical activity theory and the theory of expansive learning as frameworks for analysis. He emphasized the knowledge-creation phase, where problems are first formulated and analyzed, and in which expansive and innovative learning begins by criticizing, questioning and analyzing existing practices. The focus is on dialectical tensions and contradictions within collective activities, although these are usually ignored by approaches that focus on immediate empirical generalizations. The model is understood through the analysis of elements found in an expansive learning cycle, as innovative learning cycles do not follow any fixed order. The arguments for this method are described in [13].

Kai Hakkarainen explained the progressive inquiry process with its characteristic autonomy and selfregulation of learning processes. The progressive inquiry process utilizes diversity and "creative chaos" rather than pre-structured and strictly controlled instructional processes, which do not have any degree of freedom. The model captures certain essential aspects of a knowledge creation process, such as the importance of questions and problems, deliberately working for knowledge advancement, engagement in a deepening inquiry, and the socially shared process of inquiry. These are all essential aspects of productively working with knowledge and are routinely practiced within knowledge intensive organizations. This perspective is clarified in [18, 19].

Carl Bereiter and Marlene Scardamalia are strong advocates of student communities working together to become proficient in fields of knowledge. They introduced the concept of knowledge building communities, where students learn to work with theoretical and practical concepts as objects. They strongly advocate that students become knowledge builders and active participants in knowledge building discourse. The focus here is firstly, on problems and the depth of understanding, secondly, it focuses on decentralized, open knowledge environments for collective understanding, and the third focus area is on productive interaction within broadly conceived knowledge building communities. Knowledge building theory was created and developed for describing what a community of learners needs to accomplish in order to create knowledge. The theory addresses the need to educate people for the knowledge age society, in which knowledge and innovation are pervasive [4, 54]. Twelve identified principles of knowledge building are proposed by Scardamalia (2002) [53].

Networked expertise is defined in [19]. It refers to competences that arise from social interaction, knowledge sharing and collective problem solving, and which are embedded in the shared competence of communities and organized groups of experts and professionals. Cognition and intelligent activity are thus not limited to an individual's mental processes but also encompass socioculturally developed cognitive tools. These tools include physical and conceptual artifacts. Networked expertise is rational and is constituted in interaction between individuals, communities and larger networks that are supported by cognitive artifacts. It also co-evolves with continuously transforming innovative knowledge communities. The approach emphasizes the development of expertise, distributed cognition and shared expertise, collaborative and cultural learning, and inquiry based learning processes.

The theoretical background of Learning by Developing (LbD) has been constructed to fulfil the three metaphors of learning [32]. The first (1) perspective is a metaphor for knowledge acquisition and conceptualizing learning as a process of transferring knowledge to an individual learner. The second (2) perspective is a metaphor for participation, which emphasizes the role of social communities in learning and professional development. The third (3) perspective is a metaphor for knowledge creation, the aim of which is the purposeful generation of information and the development of related social customs. Its focus is on investigating the mediated process of knowledge generation [40, 19]. The nature of theory binding in Learning by Developing is included in Table I.

TABLE I.

THREE PILLARS OF INTEGRATIVE ACTION IN LEARNING

\begin{tabular}{|c|c|c|}
\hline \multicolumn{3}{|c|}{ Three Perspectives of Learning } \\
\hline $\begin{array}{c}\text { Acquisition } \\
\text { knowledge } \\
\text { transfer }\end{array}$ & Participation & Knowledge Creation \\
\hline $\begin{array}{c}\text { process within an } \\
\text { individual's mind }\end{array}$ & $\begin{array}{c}\text { social activities and } \\
\text { practices as bases } \\
\text { for interaction }\end{array}$ & $\begin{array}{c}\text { new knowledge } \\
\text { creation }\end{array}$ \\
\hline $\begin{array}{c}\text { new knowledge } \\
\text { objects and activities } \\
\text { are collaboratively } \\
\text { created }\end{array}$ \\
\hline process based & $\begin{array}{c}\text { based on } \\
\text { progressive }\end{array}$ & $\begin{array}{c}\text { freedom of methods } \\
\text { and support for } \\
\text { creativity }\end{array}$ \\
\hline $\begin{array}{c}\text { instructive or } \\
\text { co-instructive }\end{array}$ & co-operative & creative \\
\hline reactive & active & co-constructive \\
\hline Processing Nature & $\begin{array}{c}\text { Knowledge Sharing } \\
\text { Community }\end{array}$ & $\begin{array}{c}\text { Knowledge and } \\
\text { Innovation } \\
\text { Community }\end{array}$ \\
\hline
\end{tabular}

Ref. [19] also includes a glossary on the perspectives. The acquisition metaphor (1) of learning is a view of learning that emphasizes learning as a process of acquiring a desired piece of knowledge or knowledge structure. Knowledge is understood as a matter of the individual mind. The participation metaphor (2) of learning is a view of learning that emphasizes the process of participating in various social practices and shared, learning activities. The knowledge-creation metaphor (3) of learning is a view of learning that emphasizes learning as analogous to the processes of innovative inquiry in which an individual's initiative is embedded in productive social and institutional practices. The focus is on the process of advancing knowledge, transforming social practices and developing expertise. This view is becoming more important in modern society $[40,32,19]$.

\section{B. Role of Author and Client}

The role of the author (researcher) is in the area of research and development within information systems and multidisciplinary research projects at Laurea. The development of the three tasks' actualization in areas of research, development and education (LbD) within learning environments and frameworks are his main tasks, 
which form the basis of his work at Laurea. His interests in this research are: the actualization of the three tasks; the development of constructions and practices for actualization; and the analysis of the impacts, influences, results and weaknesses of the three tasks' actualization.

The role and interests of the client, i.e. the management at Laurea (including the vice rector and the heads of the departments of Laurea University of Applied Sciences) includes the management intensively participating in the research and development of action. The leadership style is based on a bottom-up, student-centric vision and relationship, it is also based on an $\mathrm{LbD}$ orientation and management culture and philosophy.

The interests of Laurea's management (client) in the implementation of the three tasks from 2003 to 2009 were an openness to networks instead of a closed school policy, the building and evaluation of an expertise organization rather than the maintaining of a constant school management structure, forming strategy through organisation and its evaluation, the supporting of agility, mutability and flexibility for creativity and innovations in action (this is conducted within the constructions of frameworks), contributing to the building and evaluation of the research, development and innovation orientations, and the use of a shared leadership, which is meant to balance accountability and empowerment.

\section{Method of Analysis}

The conceptual categories (open categories) for qualitative analysis were generated in the evaluation phases, the documents, transcripts and databases were analysed by the use of open coding. The relational results and development targets (axial categories) for the diagnosis and reflection phases were then composed. The data were analysed by use of the selective coding $[8,50]$.

The analysis of data for the concepts involved combines the fundamental bases of the grounded theory approach [8] with the technique used to model data from the field of systems analysis in information system's (IS) design research [5, 59]. The correspondences are illustrated in Table II.

TABLE II. REALIZATION OF CATEGORIES IN DATABASE

\begin{tabular}{|c|c|c|}
\hline \multicolumn{3}{|c|}{ Correspondence of grounded theory and analysis of IS } \\
\hline Level & Grounded Theory & ERD (database) \\
\hline classification & category & entity type \\
\hline structure & property & attribute \\
\hline value & dimension & permitted value \\
\hline association & relationship & relationship \\
\hline
\end{tabular}

There is strong correspondence [5] between these two sets of concepts: the grounded theory approach and the entity-relationship diagramming technique (ERD). This approach is a useful addition to the grounded theory scientist's toolkit when carrying out research using the grounded theory approach, especially in the building and empirical evaluation of results, relations and structures.

The implementation of the entity-relationship diagram makes a database of the results of the grounded theory approach and in its definition of terms [8]; a category is defined as a higher-level concept under which analyst group lower-level concepts; referred also as themes. In a database structure the term entity type refers to and is implemented as a table in a database. A property represents a characteristic or component of an object, event or action and provides specificity as it corresponds to the term attribute in a database. A dimension means the variation of a property over time. It is similar to permitted values in a database. The term relationship refers to a relationship between events. In a database there are relationships between tables, entity types and relationships between the attributes as well.

This type of realization of an analysis is suitable for both inductive and deductive analysis. Analytic induction is a way of building explanations in qualitative analysis by constructing and testing a set of causal links between events, actions etc. in cases where categories are based on research material in building (the building and testing of the categories that are based on the material of the research) and deduction, in which the selection of categories is based on the body of theoretical knowledge possessed by the researcher (build and test categories that are based on theory). Furthermore, the database is the first application for the testing purposes of the new categoriesentities and demonstrates whether or not a new categorization proposal will work.

\section{THE ACTUALIZED MODELS}

The four common elements (A): cyclic; thematic; linear; and relevant are proposed for a clearer specification and classification of the every day action and actualization [41]. This is because the elements can be used as full duplex and co-creative interfaces between various models of Integrative Action; and because they have similar classification categories e.g. for analyzing data for concepts [8] or as entity types in a database structure [59].

The process model of actualization is the general integrative action and research model (B) and its first contribution was the creation of a linear development framework for cyclic innovation activities with a quality perspective, it has been further developed for the implementation process of the three statutory tasks: education, research and development, and regional development. Various revisions and versions of the Integrative Action process model are presented in [39, 38, 41].

The form of action research used (C and D) exists inside the Integrative Action process; it integrates the dual imperatives of action research: 1) problem solving interest and 2) research interest [30, 33]. The limitation of this form and setting of action research is that it includes linear and relevant elements but excludes the thematic and cyclic elements of Integrative Action. This form of action research has been also actualized in the dissertation work of the author.

The Integrative Action model also includes the design science research framework (E) [34]. Design research in Integrative Action consists of activities concerned with the construction and evaluation of technological and sociotechnological artifacts to meet different needs e.g. information systems, services, models, constructs, methods or processes as well as the development of their associated theories [28, 29, 31, 20, 2]. This form of design research is actualized within information systems studies at Laurea. 
The term "research and development work", as defined by Statistics Finland, is used in integrative action research and emphasizes that research and development work is implemented in relation to education. The nature of the research and development work in Learning by Developing is thus designed and documented in the actualization process of the competence based core curriculum at Laurea [24].

The general value network (F) model has been proposed for the integration of cyclic activities and local innovation systems and service design within Integrative Action [39, 37]. The general Onion model (G) and Learning by Developing Culture $(\mathrm{H})$ have been developed and tested in order to achieve the actualization of the three statutory tasks $[15,47,42]$.

\section{A. The Four Elements of Integrative Action}

Ref. [41] proposes the common elements of all the Integrative Action models: there are several reasons and needs for a clearer specification of different Integrative Action types. The first reason is the confusion with regard to practical management. However, a completely different type of management is required for different actions in the Integrative Action model. The second reason is the core idea behind the "changing of objectivity", which refers to the balancing of subjectivity and objectivity to support creativity. The third reason is that commercially beneficial innovation and invention is impossible without radical intervention. The fourth reason is the fact that we live in a time of globalization and this means that our future business will focus more on creativity and innovation. The fifth reason is that good quality is important and requires different types of action in order to be achieved e.g. it must take creativity and innovation into account and ensure that research also includes relevance, validity and rigor. The sixth reason is that the application of the pragmatic theory of knowledge and the activity of innovation orientation both require different types of agility, action and flexibility.

Based on these reasons, a clearer definition is sorely needed in order to differentiate between and clarify different actions. Four elements are specified in [41] and are:

1) Cyclic, which supports creativity and innovation. This element emphasizes the importance of creations: (anything created) e.g. the mental creation of an intangible idea; the physical creation of something tangible; a social creation, such as spirit or trust in the interaction of a value network. The cyclic element underlines the use of the "non pragmatic" aspect of creativity as well as the freedom part of the methods and philosophies in action and design.

2) Thematic, which is used to support the structure of the co-creation of lead innovation by using thematic scopes to integrate action and cooperation within thematic regions, thematic cities, thematic living labs, ongoing $\mathrm{R} \& \mathrm{D}$, thematic curriculum, courses, and evaluations.

3) Linear, which supports the implementation of research, as well as development and action processes and work systems.

4) Relevant, which supports validity and scientific rigorousness, and ensures that the quality and action produced are relevant. This element includes a main part of quality management system with quality measures and qualitative documents of actualizations.

\section{B. Integrative Action and Research Process Model}

Integrative Action related to the three tasks $[39,38]$ and builds bridges between technologies and applications to allow research results to be turned into competences and economic success. Thus, innovation alliances should be made between various stakeholders, particularly in science, business and politics. In the Integrative Action model, vertical cooperation, namely lead innovations [10], are geared toward certain services, applications and branches with specifically coordinated support contributions from technological areas. In integrative cooperation, "technological alliances" pursuing technological objectives are jointly created with science and business through shared service platforms. This "lead innovation ecosystem" of Integrative Action includes the different types of cooperation, action and activities, illustrated in Fig. 1.

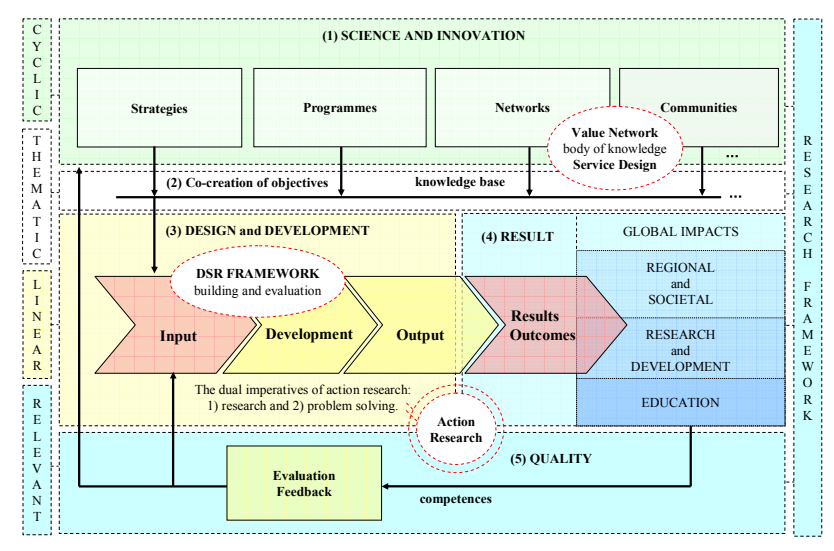

Figure 1. The general Integrative Action and Research Model. The dual imperatives of action research [30] are 1) problem solving and 2) research, which are both implemented in the linear and relevant elements. The nature of Design Science Research is linear and the Service Design influences the thematic collector. The elements were used as full duplex and co-creative interfaces. The research and development work in action (in the syllabus) bridges knowledge (the collector) and the competences (the curricula).

The main contribution of the Integrative Action and process model was the creation of a linear development framework for cyclic innovation activities that have a research, action and quality perspective [11, 21, 57].

The Integrative Action system itself is a kind of extended linear "work system" [34, 2] within an innovation system framework and a liberation process for innovative activities, rather than a fully automated process for innovation and invention generation.

Ref. [2] proposes a definition of an information system as a work system that joins strategies, the environment and infrastructures. It also includes customers, products, services, processes and activities with participants, as well as information and technologies. The work system model [2] defined in relation to the information system complements the linear and relevant elements in Integrative Action.

In practice, innovative learning cycles do not follow any fixed order [13] and methodological freedom and 
creativity are emphasized in the orientation to an innovation. Hence, the nature of an integrative process is to support rather than manage cyclic and thematic elements.

The Integrative Action model may also exist as a pure linear development environment without research e.g. if a cooperative participant or firm do not want to do research, but willingly participate in the development or problem solving part of a project.

Integrative Action focuses on mentoring, group work, professional communities, novel methodologies, living labs, spirit and flow, trust, and value in authentic value networks. Various versions and products of the Integrative Action model are demonstrated in [44, 45, 46, 48, 26, 58].

\section{Organizational Change and Action Research}

Action research aims to solve current practical problems while expanding scientific knowledge. Unlike other research methods, where the researcher seeks to study organizational phenomena but not to change them, the action researcher is concerned with bringing about organizational change while studying the process.

In the author's ongoing dissertation, action research is strongly oriented towards collaboration and change, involving both researchers and subjects. It is iterative in scope and is a continuous research process that capitalizes on learning by both a researcher (as a member of an expert community) and other participants (e.g. students, colleges, collaborators and management). In this study it is a clinical method that puts researchers in a cooperative and co-creative role.

As in this study, the philosophy for much of action research is pragmatism. Pragmatism concentrates on asking the right questions and receiving empirical answers to those questions. Action research provides a method for explaining why things do or do not work $[3,6]$.

Action research is an interventionist approach towards the acquisition of knowledge and has its foundation in the post positivist tradition. Action research assumes that a complex social process is best studied by introducing changes in that process and observing their effects. Action research links theory and practice in a cyclic process, it means binding theories and practice in the integrative action process [38]. The intention is to create a synthesis with specific knowledge that allows actors to be in a situation and have the ability to act and generate knowledge that is useful for other, similar situations.

\section{Action Research Model within Integrative Action}

The studies that have used Integrative Action at Laurea have combined theory and practice and been mainly based on Susman and Evered's (1978) classic action research process [56], as well as Checkland and Holwell's (1998) action research cycle [6], and McKay and Marshall's (2001) model [30], which also references Susman, Evered and Checkland and Howell in relation to problem-solving and research interest. This approach is widely used [3] and is, in this case, implemented inside the Integrative Action process, so the Integrative Action is seen as framework.

The action research model within Integrative Action consists of five consecutive phases that are repeated, so that the results of one process cycle feedback as inputs for the next cycle. The phases of the used action research cycle are:
(1) Diagnosis and reflection i.e. reflection on the work or the work environment from the perspective of the three statutory tasks; raising questions; and recognizing and specifying a problem area to be researched and treated with new forms of action or changed actions.

(2) Action planning, which involves learning about a problem and planning for a change by introducing and being self motivating in the co-creation of strategies, scopes, plans and implementations that use the organizational bottom-up model [41, 43, 37]. In particular, planning also connects the thematic and linear elements to action research.

(3) Action taking, which is changing the ways in which work is carried out and this is done by implementing changes and connecting the linear element of Integrative Action to action research.

(4) Evaluation, which is the assessment of the effects of change through the evaluation of the resulting new situation and the success of those changes involving the relevance of the elements of Integrative Action.

(5) Specifying learning, which reflects on what has been learnt and how a whole effort has been reported and updated to the relevant knowledge base [20] and the body of knowledge documented.

Future research interventions then continue from the next focus area that emerges from this phase. In Laurea's case it temporarily continues from the initiation stage. Slight variations in the cycle (e.g. more fine-grained phases) have been proposed, but the five steps mentioned above contain the essence of Laurea's approach, which is to induce change to tackle a problem in an organization while providing supporting research that influences the co-decisions made on what to change and how to change the linear and relevance aspects. The cycle of used action research with elements is illustrated in Fig. 2.

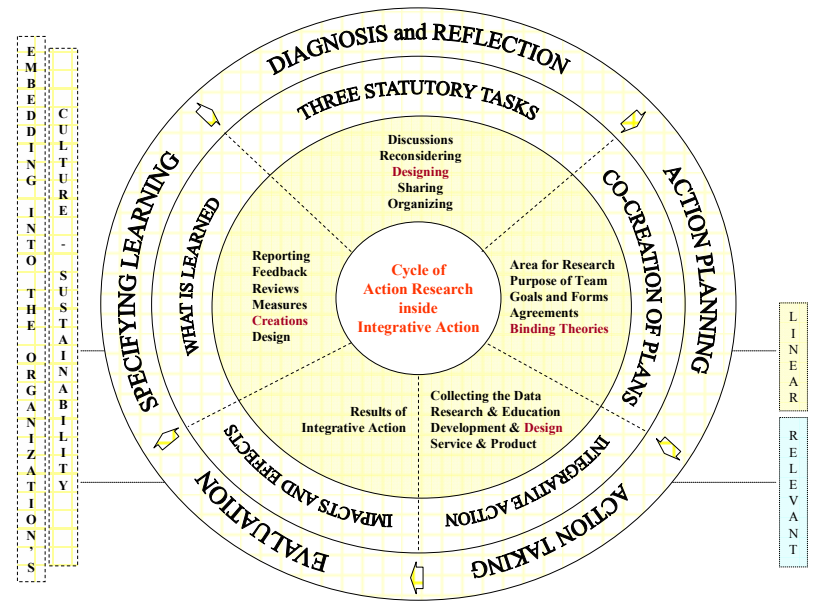

Figure 2. Action Research is implemented inside the Integrative Action model and covers the linear and relevance elements. In particular, the thematic elements exist in the action planning and specifying learning phases but the research interest [30] addresses the linear and relevant elements.

\section{E. Design Research Framework in Integrative Action}

Design research is also rooted in pragmatism in discussion [17]. For the pragmatist, truth and utility are indistinguishable as truth lies in utility. Thus, for design research, the relevance is evaluated by the utility provided to the organization and its developers. A design research 
must pass both the tests of science and practice [29]. Different terms have been used to describe this mode of research, including Design Science and Design Science Research [20]. Design research consists of activities concerned with the construction and evaluation of technological artifacts to meet organizational needs as well as the development of their associated theories.

Consequently, design research is concerned with artificial rather than natural phenomena and is rooted as a discipline in the sciences of the artificial [28]. One set of guidelines for the conducting and evaluating of a design research is the seven elements of 'DR criteria' [20]. Design research must necessarily make a dual contribution to epistemic and practical utility. Any piece of research must add to existing theory in order to make a worthwhile scientific contribution and the research should assist in solving the practical problems of practitioners, specifically problems that are either current or anticipated.

Two research methods in the information systems field with this dual orientation are design research [20, 28] and action research [3, 6, 9]. Design research consists of activities concerned with the construction and evaluation of technology artifacts to meet organizational needs as well as the development of their associated theories.

In brief, behavioural science is concerned with theories that explain human or organizational behaviour, while design research is concerned with creating new and innovative artifacts [20].

Action builds bridges from knowledge to competence and bridges design to the development and making of a commercial product, although this involves different processes, goals and theoretical assumptions. Integrative Action connects an innovation system to these perspectives through the behavioural sciences, e.g. psychological, sociological and educational in which [19] produces advanced theoretical judgements. The design of a science research framework and types of development methods are presented in the ecosystem model shown in Fig. 3.

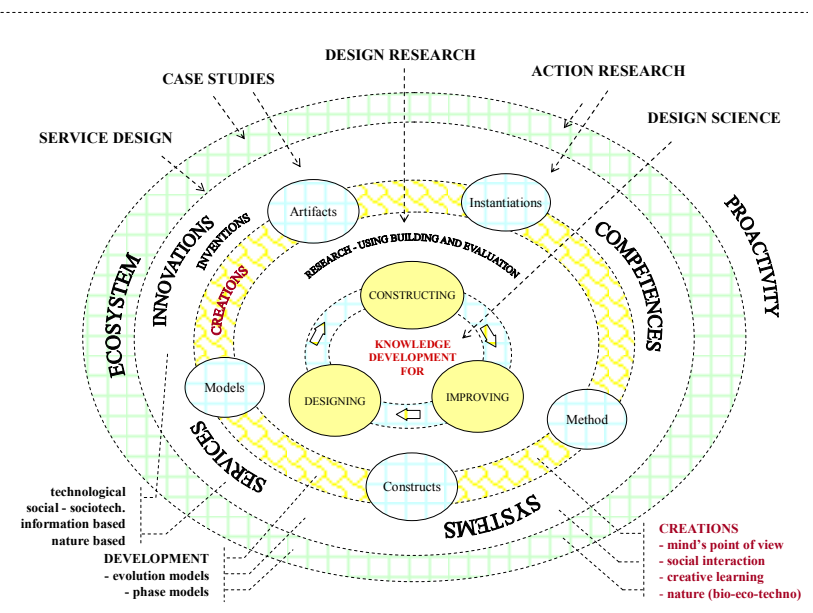

Figure 3. The term innovation is explained in the Oxford English Dictionary (OED) as 'the action or process of innovating'. So innovations are understood as: technological, social, sociotechnological, information intensive or natural processes or actions in Integrative Action. The OED also defines innovation as 'a new method, idea, product, etc.' This exists in design research [28] as the results of Integrative Action. The meaning of the term creation is seen as 'the act of creating' or 'anything created'. A student's own creations are thus emphasized when learning [19].

\section{F. Integration of Service Design and Value Networks}

The earliest contributions of Service Design to the perspective of marketing and management disciplines are connected to Shostack's (1982) article "How to Design a Service" [55], which describes the integrated design of material components, namely products and immaterial components services. A design process can be documented and codified using a "service blueprint" to map the sequence of events in a service and its essential functions in an objective and explicit manner.

Effective service marketing requires the recognition of the complex combination of products and services which make up a simple service [55]. A review "Services as Subject Matter for Design" further articulates Shostack's work and states methods of service design by Mager, (2004) [27].

The Service Design Network was launched by Köln International School of Design in 2004. Currently, the international service design network (from the perspective of marketing and management) extends to service designers around the world, professional service design agencies and educational institutions such as Laurea.

Service design is seen as the materialization of the nonmaterial messages sent by the service provider and services are "non material and living products" [27] in the perspective of the systems, innovations, inventions and results of design research [34]. The service design of information systems in Integrative Action is based on the ITIL v.3 (The Information Technology Infrastructure Library), which describes Service Design's principles, processes, technology related activities, tools, implementation and risks [22].

A participant's interests and motivation is based on value, trust and agility, the value gained from a network and the value given to a cooperative network, this "participant and participation driven network model" in which participants have a value relation to a network is called a Value Network in the Integrative Action model illustrated in Fig. 4.

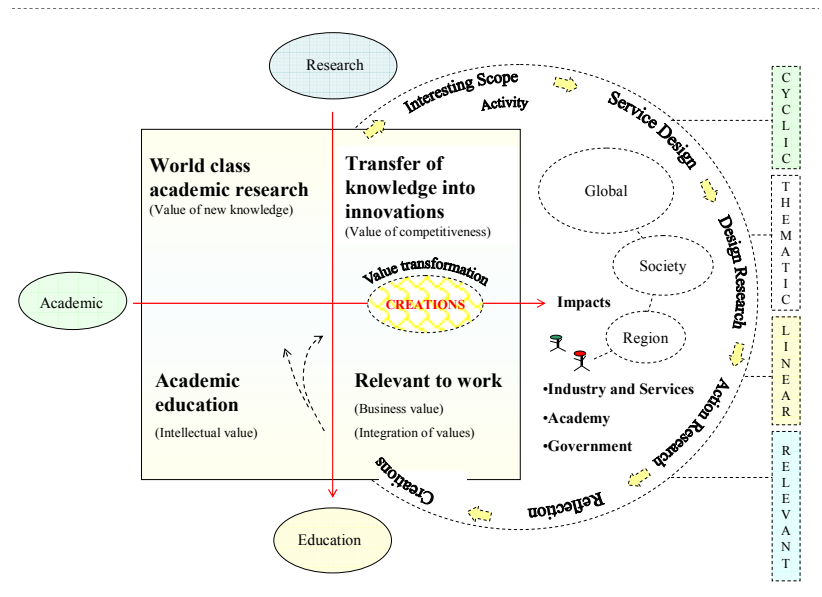

Figure 4. The term value relates to being important or beneficial. It is actualized in the perspectives of added or lost value and both possibilities are present in a value network. Learning by Developing and integration action places value networks in cyclic and thematic roles to promote student retention, engagement and achievement e.g. identity, trust; motivation; competence; equality; intensity of learning; and partnership [40]. 
The importance of value transformations and support for agility and mutability are underlined in the value network processes. Thus, competences are made more relevant to work and development and this positively influences students' employment and networking possibilities.

\section{G. Onion Model}

Ref. [15] proposed the Onion model - or cooperation model for the integration of Learning by Developing and regional development work.

Laurea is an operator in regional development, and the regional development task is linked to the whole education task. In terms of international relations, Laurea enriches its area of operation by participating in and conducting high quality international research and thus promotes its own internationalization. For students the Onion model means increased international opportunities and increased international interaction in their studies. Laurea's students are equal participants in its integrative learning environment development groups, which also include lecturers, partners and researchers. Fig. 5 presents the Onion model.

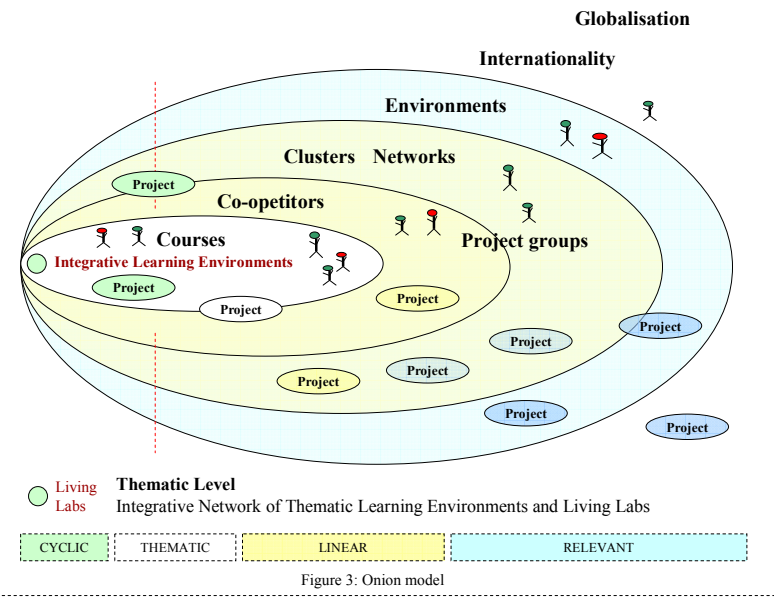

Figure 5. The Onion model extends traditional and instructional learning to a culture of Learning by Developing. It is a construction of the paradigm shift from reactive education methods to a culture of proactive knowledge creation through research. Integrative Action links

Living Labs and institutional integrative learning environments on a thematic level.

\section{H. Dimensions of Learning by Developing Culture}

Learning by Developing (LbD) is a pedagogical and collective approach in which learning is linked to an applied research and development culture. This results in learning expertise that arises from social interaction, knowledge and competence sharing, researching and problem solving related to collective objectives [15].

The "dimension model" emphasizes cooperation and creating a "learning and developing" culture, which makes it possible to include and use various scientific perspectives and methods of learning, and research and development in operation and action. The model represents a management and work philosophy based on the production of shared competence and creativity.

In the dimension model of Learning by Developing the four layers may rotate in different positions independent of each other during the implementation phases. Thus, the dimension model can be understood by implementing different elements in a learning cycle.

Innovative learning cycles do not follow any fixed process order [13], but cumulative learning is implemented as a whole, covering competences defined in a curriculum and implemented in a syllabus with "no upper limit". The proposition [47] focuses on the fact that Learning by Developing has a learning culture in which proactive knowledge development and learning have the following meanings for the participants and actors involved:

1) For the learner, LbD means growing up in a culture that focuses on expertise which arises from social interaction, knowledge sharing and collective development. This implies growing up with the lifestyle of a developer, immersing oneself in proactive learning and personal knowledge management.

2) It means increasing the value of innovations for all co-operators in applied research and development and creating new knowledge, competences, innovations, service products and practices.

3) For a university of applied sciences, it means changing its organizational and cultural role towards becoming a cooperative community regarding the creation of new knowledge and expertise. This means that an institution's own development process enriches the expertise within its community and increases its role in a value network by being a cultural prime mover and a new actor sharing innovations within a network.

4) The LbD culture contributes to regional development by having students interact with other regional participants in projects, and especially by playing a strong role in creating international links.

The dimensional model of LbD is illustrated in Fig. 5. The model underlines the relationship between cultural mutability and learning and results in the making of a more creative culture. Creativity itself is seen as the result of shared inspiration, cognition, participation and social knowledge sharing in a social context.

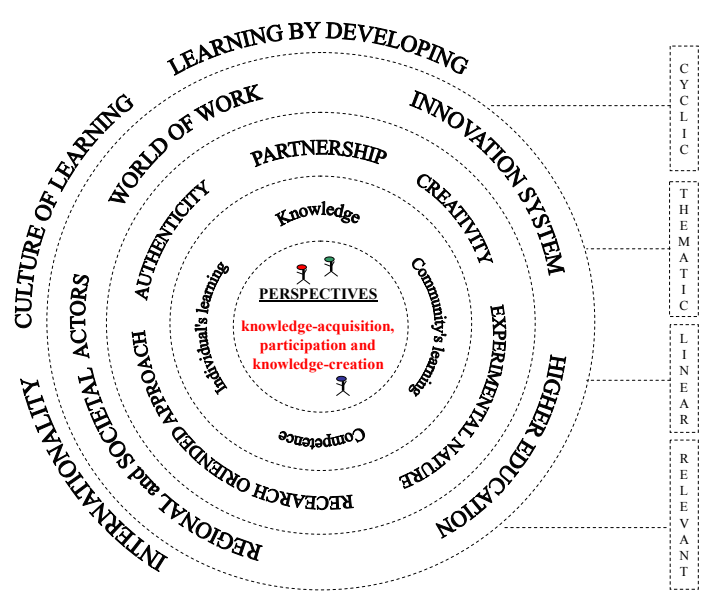

Figure 6. Learning by Developing places the students and the three perspectives of learning: knowledge acquisition, participation and knowledge creation in the centre. The derivative dimensions of learning are an individual's learning, a community's learning and the pragmatic principle that action bridges knowledge and competence in the

framework of a body of knowledge. The impacts of LbD are: support for creativity; partnership in action; a basis in authenticity; the development of an experimental nature and research that features international cooperation. 


\section{ANALYSIS}

\section{A. Analysis of Action Research Cycles}

Action research involved in integrative applications and the learning practices of the integrative implementations of the three statutory tasks was performed at Laurea University of Applied Sciences between 2003 and 2009. The Integrative Action model is used as part of a larger innovation system value network. Interventions are part of a larger network of transactions and international transformations. The Integrative Action and Learning by Developing (LbD) culture influenced Laurea's appointment as a centre of excellence in regional development for 2003-2004 and 2006-2007, and as a centre of excellence in education for 2005-2006 and 20082009.

Material of Analysis: This educational analysis includes the two action research cycles. The first cycle covers the evaluation of Learning by Development from 2003 to 2006 and the second cycle covers the evaluation of the security management unit of Laurea from 2006 to 2009. This two action research cycles include the results and effects of the excellence of education awards given by FINHEEC (Finnish Higher Education Evaluation Council). Both action research cycles are documented and presented in [33] and the evaluation reports of FINHEEC are available in $[51,52]$.

The question of analysis is: What are the main categories of the results, impacts, influences and challenges of Learning by Developing from the perspective of the results of the performed action research cycles as related to the excellence of the education? The unit of analysis is a theme or a paragraph.

\section{B. Analysis of LbD Evaluation}

Learning by Developing is reviewed in the context of higher education reform. The evaluation report [60] sets out the background to Learning by Developing within the context of a conceptual framework of Project-Based Learning and Problem-Based Learning (PBL) and provides findings from the study.

The evaluation group is: (1) Dr Shailendra Vyakarnam, who leads the team and has been in entrepreneurship education for over 20 years and based his work largely on action learning methodology; (2) Dr Katalin Illes is Director of International Corporate and Social Responsibility, AIBS, at Anglia Ruskin University, in Cambridge. Dr Illes is an experienced educator, public speaker, facilitator and personal coach; (3) Anette Kolmos, professor in Engineering Education and PBL and Chairholder for UNESCO Chair in Problem Based Learning at Aalborg University. Dr. Kolmos holds a Ph.D. in "Gender, Technology and Education" (1989); (4) Thomas Madritsch began directing the Facility Management and Real Estate Management degree program at the University of Applied Sciences in Kufstein Tirol in 2001 after acquiring more than fifteen years of professional experience in facility management.

Five main recommendations are made for the continued expansion of Learning by Developing in the report. The purpose of the evaluation study was to include a comparison between Learning by Developing, which is a Laurea created hybrid learning model with other existing project and problem based learning models. The main question of the study was: How sustainable and scalable is the model? In order to answer that the current experiences and insights of those who deliver, design and develop the whole programme of activity were sought through interviews. The evaluation report is documented and available [60].

The questions in this analysis are: What is the current situation? What are the educational differences between the Learning by Developing and Project-Based Learning and Problem-Based Learning models (PBL) today? The unit of analysis is a theme and perspective is the studies of information systems. The analyzed materials are available $[60,40,16]$;

\section{Analysis of Data Concepts}

In this analysis the categorization of the data concept uses a method based on an evolution type of development where concepts are in continuous dialogue with empirical data and practice. Since concepts are ways of summarizing data, it is important that practice is able to adapt to the data that is going to be summarized into the categories. The empirical observed categories (20022004) are transformed in the relationship model and the database and application was generated and tested in practice. The unit of analysis was a theme or an entity type.

\section{RESUlTS OF ANALYSIS}

The results are analysed from the perspective of education and learning. The contributions and implications for the research and practice of the education evaluation results were, and are, produced by the use of data analysis and empirical studies at every phase of the actualization.

The result of the action research cycles includes many of the underlined points in the evaluation of Learning by Developing, so these evaluations act as complements to each other. The result of Learning by Developing includes the methodological perspective and a comparison of the Project-Based Learning and Problem-Based Learning (PBL) and Learning by Developing orientations. The result of the data concepts proposes actualization categories and the practical utility perspective of the data concept.

\section{A. Results of Action Research Cycles}

Category of Integration: The results of FINHEEC's evaluations of education and regional impact show that the role of universities of applied sciences has developed considerably. The main focus has shifted to regional R\&D work and that a promising regional and societal influence has been achieved. Research and development is now understood as a strategic partnership instead of a commissioned project $[51,52,49,33]$. This integration perspective is challenging [7] because it needs a cultural transformation in education to succeed. It is possible to adapt and transform the Learning by Developing cultural framework, but however a peoples of organization have to create an own form of culture.

Student's Competences: Students were especially satisfied with improvements in their own development competences and universities of applied sciences have acknowledged the huge potential and realistic possibilities for implementing their statutory regional development 
tasks and other authentic societal challenges [51, 52, 60]. The paradigm shift in education methods is based on thinking regarding knowledge creation that is produced by researching as well as developing and learning in an expanding, future direction. The challenge, however, involves producing beneficial changes for institutional systems and the roles and attitudes of the students, teachers and participants [52, 33, 35].

Networked Expertise: The network expertise perspective has become more common and brought together education, $\mathrm{R} \& \mathrm{D}$ and entrepreneurs as well as whole worlds of work and innovation systems [52, 60]. In particular, the future tasks of this innovation policy are linked to the increasing participation of entrepreneurs and enterprises. Only $4.3 \%$ of enterprises considered the importance of cooperation with higher education institutes to be significant or great [7,49] and the statistics also show that only $36 \%$ of enterprises cooperated in innovation activities with higher education institutions in Finland. Research from other European countries has produced similar even more challenging results [7]. The new SHOKs (ICT clusters of the Finnish Strategic Centers for Science, Technology and Innovation) are trying to address this by connecting enterprises and higher education institutions more closely to applied research and by attempting to make use of the research produced by using it to improve an enterprise's business competitiveness.

Strengths of Networked Expertise: The analysed strengths of Integrative Action and Learning by Developing from the students' perspective are; improved employability, effective participation in authentic development projects, learning situations in which students are at the centre of the action and involve development work, highly experimental learning, raised aspirations, raised social skills, improved self confidence, the ability to take personal responsibility for results, contact with companies and organizations, the ability to train others and manage study events and the possibility to create something new $[60,51,35,12]$.

Challenges of Networked Expertise: The challenges of Integrative Action from the students' perspective are the fact that the system relies hugely on group commitment, the building of motivation and training through action i.e. how to reach strategic and important scopes and deal with new up-to-date knowledge (last known context) in a more systematic way. They also found that "learning in this way" takes much longer than "being taught". Other difficulties included finding an optimum ratio of direct inputs, scopes and initiatives, dealing with the responsibility required by authentic work situations, complexity management, the management of social situations, and a lack of ability or skills when participating in mentoring, and peer reviews and evaluation in general $[60,51,35]$.

Industry: "This method of actualization of education, research and development, and regional development involves cooperation within an employment sector to learn about the authentic developments and problems encountered at work"; "The method systematically seeks answers to problems whose solutions require new knowledge"; "The core of the model is formed by objectoriented work, which means that learning focuses on genuine development in working life"; "Learning has a clear objective and takes place through the process of generating new competence"; "Improvements in social skills and self-confidence are clear"; "More learning is needed for balancing enthusiasm between the new developers and new expertise with the managed goals of a legacy organization" $[35,40]$.

Is Learning by Developing a New Learning Innovation? The evaluation report (2005) notes that Learning by Developing and Integrative Action empirically demonstrate a learning framework that includes coinstructing, co-operating and co-constructing, which can further extend students' collaborative work to cooperation within the Finnish innovation system [52]. Two underlined results of that evaluation are: "The learning environment is conceived broadly from the perspectives of the workplace, the region, a science university and even incipient internationalisation". This adds credibility to the future significance of the pedagogical development work. In addition, the integrated pedagogical approach is based on student oriented activities and focuses on future workplace skills. Thus, it is an excellent approach for contributing entrepreneurial elements to education at universities of applied sciences, especially as the overall mission of universities of applied sciences is seen as consisting of practical operations that integrate the three tasks. It is a procedural and proactive model that integrates students' everyday activities with the development of the employment sector, which is based on working towards solving genuine problems. The model's theoretical foundations are solid and built on carefully considered analyses of the links in the operation [52].

Incipient Category of Internationalization: The notion of "an incipient internationalisation" $[51,52,60]$ addresses international expertise services. It is a model and practice for integrating the three tasks and a strategy when using international partnerships to bring in expertise from other higher education institutions and similar labour market clusters from around the world. This requires doing regional development tasks through international research-trainees and their networks in way that uses knowledge transformation to and from regions. Thus, part of the overall mission of universities of applied sciences is seen as consisting of practical operations that integrate the three tasks with international co-operation and networks. The target of the International Expertise Service is to develop a procedural and proactive practice that integrates students' everyday activities with the development of the international employment sector, which is based on working towards solving genuine problems and enabling the transformation of knowledge as well as competences in the global domain.

Category of immaterial and material resources: The analysed strengths from the perspective of resources are; that co-operational and co-creative strategies are managed and actualized; that an organization's learning occurs in the actualization process; that vision is based on management and leadership culture and balances accountability and empowerment; that the enforcement of international transformations of competences and applied research broadens research horizons; that economic balance is improved due to the improved understanding and managing of cyclic and linear components of an economy; that agility in action and culture is seen as possible and that influences, scopes and results are emphasized. The challenges are the pressure placed on management because transformation to Learning by 
Developing is difficult and requires ability and tolerance, and that authority breaks down due to the influence of the expertise culture. Additionally, the integrative system challenges the community of higher education institutions $[51,52,60]$.

Implications for Theory: The Learning by Developing Model contributes to the body of pedagogical literature by seeking to align competence and knowledge creations in different and complementary ways. It provides a conceptual and tested framework and model (theory) for inter-operative learning that includes creativity as value in networks and organisations $[51,52]$.

\section{B. Results of Learning by Developing Evaluation}

The analyzed report [60] sets out the background to Learning by Developing within the context of a conceptual framework of Project-Based Learning and Problem-Based Learning (PBL) [16]. It is noted that: "the Learning by Developing is clearly much more than PBL there has been a deliberate level of ambiguity built into the implementation of the whole process. It seems that the ambiguity is celebrated by some (not by many) because it allows students to experience what the world of work is really like; to try and solve problems using their own initiative and to find a level of self confidence and aspiration that might not be possible through the more conventional methods that are known and loved in higher education institutions" [60].

This analysis proposes that the question concerns complementation rather than differences. This raises the question: How can the design science research framework work without problems? The simple answer is that it can't work without problems on the linear level. However, by extending the Learning by Developing and Integrative Action processes to the world of PBL and interaction and co-creation with cyclic innovation systems, regarding issues, scopes, strategies, networks, creativity, innovations, and inventions, problems can be better aligned to the thematic scopes and innovation system.

The Information System Framework [20] presents a conceptual framework for understanding, executing, and evaluating information systems research that combines behavioral science and design science paradigms.

The contribution of the presented extension to the Information System Framework in [34] is to add more support for creativity to it, because of the importance of mental creativity in information system design. This is applied within the Information System Framework that co-operates within an Integrative Action process, because Integrative Action, in general, links value networks and motivation based creativity (which is rather non pragmatic i.e. it is a thought based activity) to linear development. An "early innovation issue, a hidden innovation or method" may exist without a problem and so it is necessary that creativity and co-creation is supported [40]. This view focuses on a paradigm shift from problem based thinking to the support of creativity and "learning by design" thinking in an Information System Framework (from problems to social scopes and activities).

"The most obvious difference is in the focus of the formulated principles, whereas the two PBL-models focus on the curriculum, the LbD model focuses on the learning outcomes and the external relationships more than the curriculum. However, the formulation of the three different models has taken place at two different times and has served different requirements from society" in [60].

The new competence-based core curriculum and thematic curriculum are furthered and actualized also in the case of the information systems at Laurea. Learning by Developing focuses on competences and the principle that action bridges knowledge in the competences, because the competences are underlined in the innovation system [24].

The comparison of Inquiry- and Problem-Based Learning and Project-Based Learning with the Learning by Developing culture is shown in Table III.

TABLE III.

ANALYSIS OF LEARNING ORIENTATIONS

\begin{tabular}{|c|c|}
\hline \multicolumn{2}{|c|}{ Complementary Orientations in Integrative Action } \\
\hline $\begin{array}{c}\text { Inquiry- and Problem-Project- } \\
\text { Based Learning (PBL) }\end{array}$ & $\begin{array}{c}\text { Learning by Developing( }(\text { LbD) } \\
\text { Culture of Learning }\end{array}$ \\
\hline focuses on problem-solving & $\begin{array}{l}\text { focuses on creativity and } \\
\text { innovations }\end{array}$ \\
\hline $\begin{array}{l}\text { emphasis on meaningful } \\
\text { learning }\end{array}$ & $\begin{array}{l}\text { emphasis on innovation and } \\
\text { creativity in learning }\end{array}$ \\
\hline project-based instruction & $\begin{array}{l}\text { using transformations of different } \\
\text { orientations }\end{array}$ \\
\hline objectivity in evaluation & $\begin{array}{l}\text { evaluation is an entity for } \\
\text { creativity }\end{array}$ \\
\hline $\begin{array}{l}\text { problem-based and defined } \\
\text { objects }\end{array}$ & creative scopes and objects \\
\hline problem domain & science and innovation system \\
\hline $\begin{array}{l}\text { learning to work in a } \\
\text { community }\end{array}$ & $\begin{array}{l}\text { regional, national and global } \\
\text { impacts }\end{array}$ \\
\hline many ways to solve problems & $\begin{array}{l}\text { creative collaborative work with } \\
\text { scopes and themes }\end{array}$ \\
\hline relevance of problems & $\begin{array}{l}\text { value of creativity and } \\
\text { innovation }\end{array}$ \\
\hline $\begin{array}{l}\text { learning based on problem- } \\
\text { solving }\end{array}$ & $\begin{array}{l}\text { innovation-oriented learning and } \\
\text { social cooperation }\end{array}$ \\
\hline problem-based curriculum & competence-based curriculum \\
\hline $\begin{array}{l}\text { knowledge connected to } \\
\text { problems }\end{array}$ & $\begin{array}{l}\text { knowledge interconnected by } \\
\text { themes and objects }\end{array}$ \\
\hline $\begin{array}{l}\text { learners gravitate by nature of } \\
\text { problem }\end{array}$ & $\begin{array}{l}\text { learners gravitate by abilities and } \\
\text { interests }\end{array}$ \\
\hline reactive response & proactive results and impacts \\
\hline $\begin{array}{l}\text { interpersonal skills and } \\
\text { teamwork }\end{array}$ & $\begin{array}{l}\text { sustainable and complementary } \\
\text { action of community }\end{array}$ \\
\hline teacher as the facilitator & teacher as coacher and counselor \\
\hline $\begin{array}{l}\text { meaningful learning as the } \\
\text { highest quality }\end{array}$ & $\begin{array}{l}\text { interest and value for students as } \\
\text { the highest quality }\end{array}$ \\
\hline teamwork and individuals & $\begin{array}{l}\text { social, networked community, } \\
\text { groups, value network }\end{array}$ \\
\hline $\begin{array}{l}\text { external impacts controlled and } \\
\text { managed }\end{array}$ & $\begin{array}{l}\text { high risk of undesirable external } \\
\text { impacts }\end{array}$ \\
\hline institutional top management & $\begin{array}{l}\text { vision-based top management, } \\
\text { bottom-up model }\end{array}$ \\
\hline $\begin{array}{l}\text { mainly linear process inside the } \\
\text { LbD culture }\end{array}$ & $\begin{array}{l}\text { orchestration framework of } \\
\text { cyclic and linear processes and } \\
\text { thematic activities }\end{array}$ \\
\hline
\end{tabular}

"Sometimes the problems consist of theoretical questions in PBL and that is allowed and accepted as are real life problems. In that sense PBL has a broader scope compared to LbD", which is proposed in [60].

There are two imperatives in Learning by Developing in [36]: In general, if the innovation center based objectives and lead innovations are used in education, then learning action creates deeper and more relevant knowledge and competence for expertise communities than a workplace's or student's own themes or areas of interest [25]. This is reasonable because the innovation 
topics and research areas for innovation centers are deeply analyzed and verified, from a future perspective. Furthermore, this does not include any major contradiction with creativity as it is possible to keep the creative scopes and themes of the innovation center flexible, motivating and creative enough for students in the Integrative Action process [40].

The second empirical perspective and imperative takes place in form of the two examples: the security and ICT cases SATERISK (risks of satellites) and FLOODWARE (flood readiness and research of flood systems), which are both large, global R\&D projects. The Integrative Action model was implemented to enable knowledge creation and the globalization of transformations. The idea, foundation, focus, themes, topics and spirit of SATERISK were further elaborated by students, so SATERISK is purely a student innovation and creation. This means that student driven creations and designs also lead to the thematic collector and that innovation center based objectives may be the co-creative creations of students. Ref. [19] produces advanced judgments that are essential for this perspective of creativity in learning as they focus on students' own creations (designs) and promote the use of scaffolding (structures in learning). Hence, all co-instructive, cooperative and co-constructive creativity is supported in the Learning by Developing culture [33].

Support for creativity is clearly different inside a linear problem domain when compared to cyclic and thematic activities. The supporting of creations, ideas, issues and visions is different to the supporting of creativity inside a framework involving the building and evaluating process of artifacts. In an Integrative Action process Learning by Developing includes linear and relevant elements, so it also covers the world of PBL, while the progressive inquiry process, the rational development process $[23,14]$ and the project-based learning process can be actualized in the linear and relevant elements. Integrative Action joins the thematic and cyclic elements to linear and relevant action.

A future scope of this analysis should include the questions: How important are creativity, innovations and inventions to the future of centers of education and learning? How important is this perspective for our culture, society and region? Is it necessary to measure the integrative results and impacts? How can we measure the benefits of the affects and influences? How can we further the evaluation of ecosystems for supporting creativity, innovations and inventions?

Summing up the differences between Learning by Developing and PBL in this analysis it is apparent that the major difference is that Learning by Developing has a learning culture and framework. It also has cyclic and thematic elements and components, such as innovation systems, a value network, methodological and creative freedom, thematic regions, thematic cities, thematic living labs, thematic research scopes, thematic curricula and thematic implementations.

\section{Results of the Data Concepts}

Based on the empirical categorization (2002-2004): the analysed, implemented and tested entities and relations of the integrative action are: theme (one) to (many) study unit (one) to (many) syllabus (one) to (many) teaching (many) to (one) teacher (one) to (many) projects (many) to (one) project (one) to (many) project data (many) to syllabus (one); time period (one) to period data (many) to syllabus (one). Furthermore, a student group (starting studies at the same time) has a "one to many" relationship to the category of syllabus. In addition, the teacher category has a relationship to various works e.g. teaching, projects, mentoring and agreement based works. A synonym used by Learning by Developing for the category of projects is undertaking, or more simply agreements. The logic of action and actualization is illustrated in Fig. 7.

The implementation of the presented entities to the information system is called as REDTAS and was used from 2002-2006 at Laurea. REDTAS is an acronym for Resource and Time Planning System for the actualization of the three tasks: research (R), education (E) and development (D). Further development work is continuing with the product called the SOLEOPS being developed in cooperation with Solenovo Ltd. The "OPS" part of the name refers to a curriculum.

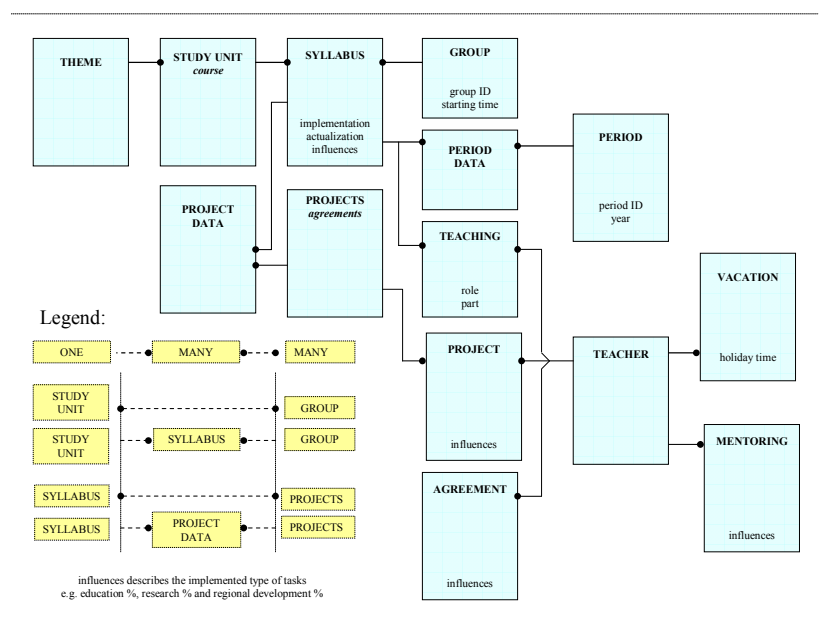

Figure 7. The categories are transformed to entities and implemented and tested in the database. The generation of the categories is inductive i.e. it observes that the categories are based on the material and practice of the researchers e.g. on the practice of the actualization of the three tasks. The testing of the database is deductive; it binds the model (theory) and the practice of the actualization process. This type of development is more evolutional than the phase-model.

\section{DISCUSSION}

The Integrative Action model aims to answer future questions such as; What system architecture and philosophy should be used in the management of a networked international innovation system and regional development in higher education? It also provides a conceptual framework for understanding the management of competence creation in higher education, which ensures that the system or process does not prevent creativity or innovation from occurring.

The perspectives of challenges in Learning by Development are also discussed with reference to evaluation process and the management of complexity. Both perspectives have some commonalities in education and learning. Firstly, students know the actual situation better than their teacher. Secondly, peer evaluation maintains spirit and equality better than a teacher's evaluation can. Hence, peer reviews and subjectivity in evaluation and complexity management are promising 
perspectives and therefore the development work of quality management at Laurea includes [11, 21, 22].

Alter's proposition [2] "Defining information systems as work systems" from the perspective of evaluation and evolution based developing raises the question: Should cocreative peer and result evaluation and evolution development include: processes and activities; the cocreative influences of participants; information and knowledge (also tacit); technology; products and services; and co-created or implicit or explicit activities within a local and global innovation system?

It would seem that this integrative model further extends the conceptualisation of knowledge, competence and creativity at the level of the individual participant. Thus, it furthers a shared and "evolution type development" of a body of knowledge and a community, e.g. the body of knowledge in a living labs community [26].

The future role of Integrative Action and Learning by Developing is discussed from the perspective of an information system and services. The co-created vision emphasizes a building and testing of the integrative results by use of "last mile research" [Nunamaker], presented in Fig. 8.

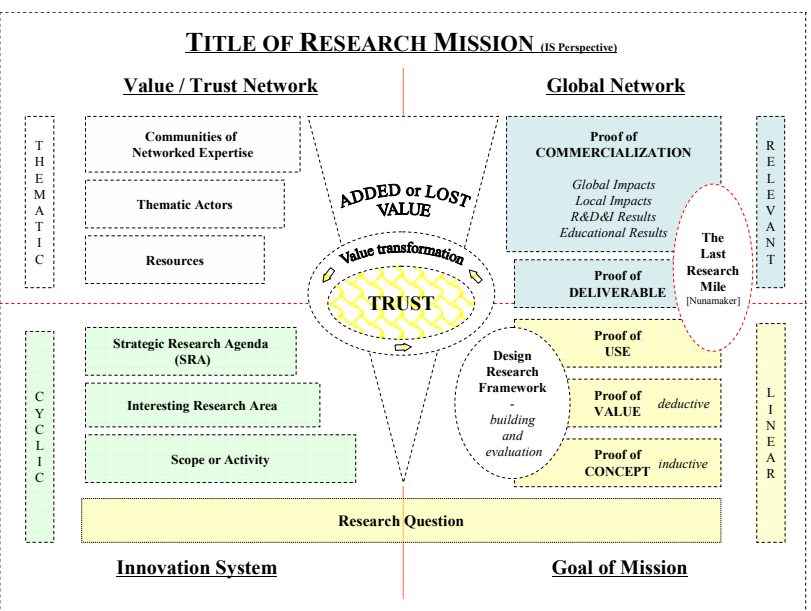

Figure 8. The "Last Mile Research" perspective of the integration and actualization was discussed with Professor Jay F. Nunamaker at Laurea in September 2009. The vision underlines: the TRUST within value networks; added or lost value in co-operation; and the importance of last mile research in information systems' design science research and service design.

In discussion with Professor Nunamaker at Laurea it was realized and proposed that: an "interesting idea is naive until someone takes it through the last mile; understanding is rudimentary until someone goes through the last mile; everything that is done is trivial until it has been worked through the last mile" [Nunamaker].

This discussion should encourage us to continue our work and the furthering of Integrative Action and Learning by Developing within the emphasized perspective of last mile research.

\section{ACKNOWLEDGMENT}

I want to thank all my students for their research and development work and their contribution to Integrative Action and Learning by Developing.

\section{REFERENCES}

[1] ACT351. The Act, 351/2003, (In Finnish). (http://www.finlex.fi/fi/laki/alkup/2003/20030351)

[2] S. Alter, "Defining information systems as work systems: Implications for the IS field", European Journal of Information Systems 17, No 5, 2008, pp 448-469. (doi:10.1057/ejis.2008.37)

[3] R. Baskerville and A. Wood-Harper, "Diversity in information systems action research methods", European Journal of Information Systems (7), 1998, pp. 90-107.

[4] C. Bereiter, "Design Research for Sustained Innovation", Cognitive Studies, Bulletin of the Japanese Cognitive Science Society, 9(3), 2002, pp. 321-327.

[5] M. Brandy, "Use of entity/relationship diagramming as a technique in the grounded theory approach to social science research", Irish Academy of Management Annual Conference, Dublin Institute of Technology, 2000.

[6] P. Checkland and S. Holwell, "Action Research: Its Nature and Validity", Systemic Practice and Action Research, volume 11, no. 1, 1998, pp. 9-21. (doi:10.1023/A:1022908820784)

[7] Community Innovation Statistics CIS (2007), Science and technology, EUROSTAT 81/2007. (http://epp.eurostat.ec.europa.eu/)

[8] J. Corbin and A. Straus, Basics of Qualitative Research: Techniques and Procedures for Developing Grounded Theory. $3^{\text {rd }}$ ed. Los Angeles: Sage Publications, 2008.

[9] R.M. Davison, M.G. Martinsons and N. Kock, "Principles of Canonical Action Research", Information Systems Journal (14:1), 2004, pp 65-86.

[10] Digital Business Ecosystems, European Commission, Information Society and Media, 2007. (http://www.digital-ecosystems.org/)

[11] EFQM Excellence Model (1999) (Brussels, EFQM). The EFQM Excellence Model. (http://excellenceone.efqm.org/).

[12] EIS (2007) "European Innovation Scoreboard 2007 Analysis of innovation performance". (www.nordforsk.org/european_innovation_scoreboard_2007).

[13] Y. Engeström, "Expansive learning at work. Toward an activitytheoretical reconceptualization", Journal of Education and Work, vol. 14, no. 1, 2001, pp. 133-156. (doi:10.1080/13639080123238)

[14] T. Erl, Service-Oriented Architecture. Concepts, Technology, and Design. Boston: Prentice Hall, 2005.

[15] M. Fränti and R. Pirinen, Tutkiva oppiminen integratiivisissa oppimisympäristössä. Laurea Publications, Edita, 2005 (in Finnish).

[16] E. Graaff and A. Kolmos, (ed.) Management of Change, Implementation of Problem-Based and Project-Based Learning in Engineering, Sense Publisher, Rotterdam, 2007.

[17] S. Haack, "The Pragmatist Theory of Truth", British Journal of Philosophical Science (27), 1976, pp 231-249.

[18] K. Hakkarainen, K. Lonka and L. Lipponen, Tutkiva oppiminen. Älykkään toiminnan rajat ja niiden ylittäminen. Porvoo: WSOY, 1999 (in Finnish).

[19] K. Hakkarainen, T. Palonen, S. Paavola and E. Lehtinen, Communities of Networked Expertise: Professional and educational perspectives. Amsterdam: Elsevier, 2004.

[20] A.R. Hevner, S.T. March, J. Park and S. Ram, "Design Science in Information Systems Research", MIS Quarterly (28:1), 2004, pp 75-105.

[21] ISO/DIS 9000:2000 (1999) International Organization for Standardization. (www.iso.org/iso/home.htm).

[22] ITIL v.3 Service Design (2007). The Information Technology Infrastructure Library, the Stationery Office, London.

[23] I. Jacobson, G. Booch and J. Rumbaugh, The Unified Software Development Process. Addison-Wesley Professional, 1999.

[24] O. Kallioinen, (ed.) The Competence-Based Curriculum at Laurea, Laurea Publications, Edita, 2007.

[25] H. Kotila and P. Auvinen, Tie vastuulliseen johtajuuteen palveluliiketoiminnan arviointeja. HAAGA-HELIA Publications. Helsinki, 2008 (in Finnish).

[26] Laurea Living Labs (LLL) is a member of the European Network of Living Labs (ENoLL). ( www.openlivinglabs.eu )

[27] B. Mager, Service Design a Review, Köln International School of Design, Service Design Network, 2004. 
[28] S.T. March and G.F. Smith, "Design and Natural Science Research on Information Technology", Decision Support Systems (15:4), 1995, pp 251-266,

[29] M.L. Markus, A. Majchrzak and L. Gasser, "A Design Theory for Systems That Support Emergent Knowledge Processes", MIS Quarterly (26:3), 2002, pp 179-212.

[30] J. McKay and P. Marshall, "The Dual Imperatives of Action Research", Information Technology and People, 14(1), 2001, pp. 46-59. (doi:10.1108/09593840110384771)

[31] J. Nunamaker, M. Chen and T. Purdin, "Systems Development in Information Systems Research", Journal of Management Information Systems, 7 (3), 1990-91, pp 89-106.

[32] S. Paavola, L. Lipponen and K. Hakkarainen, "Models of Innovative Knowledge Communities and Three Metaphors of Learning”. Review of Educational Research. 749(4), 2004, pp. 557-576. (doi:10.3102/00346543074004557)

[33] R. Pirinen, "Integrative Action and Learning by Developing (LbD): Canonical Action Research". IEEE Education Society. In International Conference (ICL 2009), 23-25 September, Villach, Austria. 2009.

[34] R. Pirinen, "Research Framework of Integrative Action". Americas Conference on Information Systems (AMCIS 2009). 6-9 August, San Francisco, California, USA. 2009.

[35] R. Pirinen, "Integrative Learning Environments in Perspective of Globalization Case": Globalization Models and Effects in Higher Education. International Multi-Conference on Engineering and Technological Innovation (IMETI 2009). 10-13 July, Orlando, Florida, USA, 2009, pp. 156-161.

[36] R. Pirinen, "Integrative Action in Higher Education, Industry Collaboration and Regional Development: An Action Research Approach". Proceedings of ICEIRD 2009, 24-25 April, Thessaloniki, Greece, 2009, pp. 221-230.

[37] R. Pirinen, J. Tarkkanen and J. Teräs, "Integrative Action Models in Regional Development: Applied Triple Helix". Proceedings of TRIPLE HELIX XII Conference, 17-19 June, Glasgow, Scotland. 2009.

[38] R. Pirinen, "Integrative Action and Process Mode", International Conference on education and educational technology (EDU'08). WSEAS, 21-23 November, Venice, 2008, pp. 89 - 94.

[39] R. Pirinen, "Integrative Learning Environments in perspective of Regional Development". In Pascal International Conference, 2830 May, University of Limerick. 2008.

[40] R. Pirinen, "Integrative Action Process in Perspective of the Three Metaphors of Learning". International Journal of Education and Information Technologies. Issue 4, Volume 2, 2008, pp. $226-$ 237.

[41] R. Pirinen, "Integrative Action Process in the Perspective of Globalization". International Journal of Emerging Technologies in Learning (iJET). IEEE Education Society. Volume 3, Special Issue: ICL2008, 2008, pp. 61-68.

[42] Pirinen, R. and Fränti M. "Framework and Culture of Proactive Competencies Learning - Learning by Developing". International Conference on education and educational technology (EDU'08). WSEAS, 21-23 November, 2008, pp. $83-88$.

[43] R. Pirinen and M. Fränti, "Integrative Learning Environments in Perspective of Globalization Models and Effects in Higher Education". IEEE Education Society. In International Conference (ICL2008), 24-26 September, Villach, Austria, 2008.

[44] R. Pirinen and J. Rajamäki, "Synthesis of Learning by Developing and Virtual Learning Case: Laurea's Network Design Specialization Studies". WSEAS TRANSACTIONS on ADVANCES in ENGINEERING EDUCATION. Volume 5, ISSN: 1790-1979, 2008, pp. 624-634.

[45] R. Pirinen and J. Rajamäki, "Modeling and Simulation of Critical Infrastructures Case: Rescuing of Intelligence and Electronic Security Core Applications (RIESCA)". In European Computing
Conference. (ECC 08), WSEAS, 11-13 September, Malta, 2008, pp. 403-408.

[46] R. Pirinen, J. Rajamäki and L. Aunimo, "Rescuing of Intelligence and Electronic Security Core Applications (RIESCA)". WSEAS TRANSACTIONS on SYSTEMS. Volume 7, ISSN: 1109-2777, 2008, pp. 1080-1091.

[47] R. Pirinen and M. Fränti, "Learning by Developing". Information Technologies: Theory, Practice, Innovations. In Alytus International Conference, 6-7 December, Alytus College. 2007.

[48] J. Rajamäki and R. Pirinen, "Linkage of Learning by Developing and Virtual Learning. Case: Network Design Specialisation Studies". In: European Computing Conference (ECC 08), WSEAS, 11-13 September, 2008, pp. 397-402.

[49] P. Rauhala, R\&D “Activities in Finnish Universities of Applied Sciences Promoting Regional Development” in Laine et al. (ed.), Higher Education Institutions and Innovation in the Knowledge Society, ARENE, Nord Print, Helsinki. 2008, pp. 95-101.

[50] C. Robson, Real World Research, 2nd Ed, Blackwell, Oxford. 2002.

[51] M. Saarela, P. Jaatinen, K. Juntunen, A. Kauppi, L. Otala, V-M. Taskkila, K. Holm and M. Kajaste, Ammattikorkeakoulujen laatuyksiköt 2008 - 2009, Publications of the Finnish Higher Education Evaluation Council, 2:2009, (in Finnish).(http://www.kka.fi/files/668/KKA_209.pdf)

[52] H. Salminen and M. Kajaste, (ed.), Laatua, innovatiivisuutta ja proaktiivisuutta, Ammattikorkeakoulujen koulutuksen laatuyksiköt 2005-2006, Publications of the Finnish Higher Education Evaluation Council, 3:2005, (in Finnish). (http://www.kka.fi/files/93/KKA_305.pdf)

[53] M. Scardamalia, "Collective Cognitive Responsibility for the Advancement of Knowledge". In B. Smith (ed.), Liberal Education in a Knowledge Society. Chicago: Open Court, 2002, pp. 67-98.

[54] M. Scardamalia and C. Bereiter, Knowledge Building. In J. W. Guthrie (Ed.), Encyclopedia of Education. $2^{\text {nd }}$ edition. New York: Macmillan Reference, USA. 2003.

[55] L. Shostack, "How to design a Service", European Journal of Marketing, Bradford, Vol. 16, Issue 1, 1982, pp 49-64. (doi:10.11 08/EUM0000000004799)

[56] G. Susman and R. Evered, "An Assessment of the Scientific Merits of Action Research". Administrative Science Quarterly, 23 (4), 1978, pp. 582-603. (doi:10.2307/2392581)

[57] The British Quality Foundation (BQF) is an independent, not-forprofit organization founded in 1993 by the DTI and leading businesses. (http://www.quality-foundation.co.uk/links.htm).

[58] The International Service Design Network activates the development of new services for public sectors and companies. (www.service-design-network.org).

[59] J. Ullman and J. Widom, A first course on database systems, $2^{\text {nd }}$ ed., Prentice-Hall. 2002.

[60] S. Vyakarnam, K. Illes, A. Kolmos and T. Madritsch, Making a Difference. A Report on Learning by Developing - Innovation in Higher Education at Laurea University of Applied Sciences, Laurea Publications, Edita, Helsinki, 2008.

\section{AUTHOR}

R. Pirinen is with the Laurea University of Applied Sciences, Vanha maantie 9, 02650 Espoo, Finland (e-mail: rauno.pirinen@laurea.fi).

This article was modified from a presentation at the International Conference of Interactive Computer Aided Learning ICL2009, September 2009 in Villach, Austria. Submitted 15 October 2009. Published as resubmitted by the authors on 2 November 2009. 